\title{
The Impact of Financial Intelligence on Commercial Banking from the Perspective of Transaction Cost
}

\section{Xu Zhaoyi, Cheng Xinyu}

\author{
Hunan University, Changsha, Hunan, 410082, China
}

Key words: financial technology; commercial bank; transaction cost; financial service

Abstract:Based on the transaction cost from the perspective of financial intelligence influence for commercial banks, analyzes the transaction cost of commercial banking business, including financial intermediation costs, operating costs and management costs of credit market. In the field of asset management, payment clearing and information authentication, this paper discusses the impact of financial intelligence on the transaction cost of commercial banks. Through a comprehensive analysis of the commercial bank gives the relevant policy: digital exchange system to establish multi-party cooperation, promoting multi center transaction; development based on block chain of credit since the financial intermediary platform, to realize the instant payment; to build digital identity inter-bank sharing platform, understand customer needs and reduce financial risks.

\section{Introduction}

Financial intelligence will be an important development direction of the future of finance, in the long run it will bring a revolutionary impact on the traditional commercial banking finance, science and technology development will become the main driving force for the future of finance. On the one hand, the financial Internet and Internet penetration of financial help to enhance the efficiency of financial intermediation and has become an irresistible trend today. China's third party Internet payment transaction statistics as shown in figure 1. On the other hand, the development of artificial intelligence and mobile Internet to promote financial services, connecting people and, through artificial intelligence technology, information can predict, decision-making, action to help build the standardization, risk modeling, intelligent control system, and promote financial development from $^{[1-2]}$.

Transaction cost, transaction cost can be divided into broad and narrow the transaction cost, the generalized cost including negotiation, contract and obtain information needed to use all the resources, the transaction cost is narrow contract the cost cost. Scholar Stiglitz first from the point of view of the financial cost of information and intelligence of the transaction cost savings, they stressed the importance of information cost in the transaction cost, information cost that is the core of the transaction cost, and financial intelligence is the decrease of the cost of information to achieve the aim of saving transaction cost ${ }^{[3]}$. Cai Yangping from the perspective of reducing transaction costs, that financial intelligence is to reduce transaction costs for the purpose of the practice of Inclusive Finance is the most effective way. From the perspective of transaction cost, the paper analyzes the function of financial intelligence to reduce the financing cost of small and medium-sized enterprises, but also thinks that financial intelligence is not the key to solve the financing problem of Li Zhiqiang. They argue that there is a huge pool of profits in the field of trade, and a slight decline in transaction costs will lead to a substantial increase in wealth ${ }^{[4-5]}$.

The development of financial technology will greatly reduce the transaction costs, this trend is a trend which cannot be halted, this is an era of asset securitization by means of Internet financial platform, intelligent enterprise is to subvert the traditional financial industry trend. The direct object of this shock is the leading force in China's financial market ${ }^{[6]}$. Because of the higher rate of return, bank deposits have begun to flow out of the banking financial intelligence products, which directly hit the commercial bank liabilities business, making the total deposits of commercial banks began to decline, and further affect the other business of commercial bank. However, financial intelligence is not only a variety of Internet based financial products based on the IMF, but also because of their 
involvement in the brokerage, banking, insurance and trust. The emergence of intelligent financial mode seems to have changed the traditional financial industry, some Internet Co also is the rhetoric on the traditional financial industry revolution ${ }^{[7-8]}$.

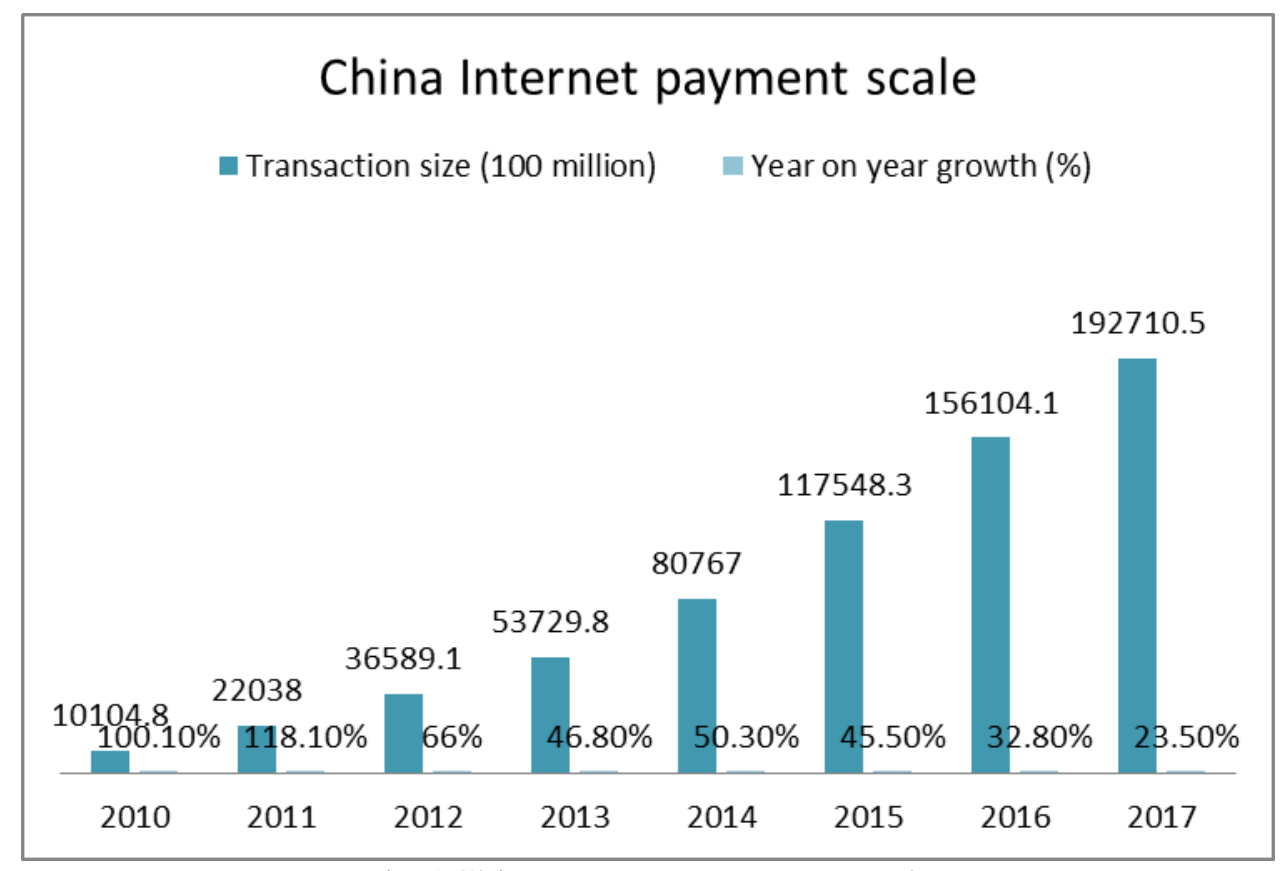

Fig.1China Internet payment scale

\section{The composition of transaction cost in commercial banking}

\subsection{Financial intermediation costs}

Compared to the traditional financial model, the following advantages of financial intelligence will have a certain impact on the traditional commercial banks, commercial banks, the role of financial intermediation is weakening. In the traditional financial model, commercial banks as a financial intermediary, in addition to the stock and other direct investment mode of all investment activities are centered on commercial banks. The development of financial intelligence has driven the pace of financial disintermediation, direct financing instead of indirect financing, financial intelligence mode, the bank lost its dominant position, directly investing and financing to achieve capital docking. Reduce the cost of investment and financing, improve the efficiency of investment and financing, bypassing the banks, the lower threshold to meet the financing needs of the grassroots.

\subsection{Market operation cost}

Compared with the traditional banks and other financial institutions, financial intelligence is the network virtual space to carry out financial business based on the issuance of financial products, trading and payment of money can be directly online, which greatly reduced the transaction cost. At the same time, the Internet platform eliminates the huge cost of the traditional banking industry and the cost of employing a large number of human resources, greatly reducing the cost of investment, operating costs and management costs. It is estimated that the cost of Internet business and traditional banking and other financial institutions, the ratio of the cost of business can often reach 1:100 or even 1: 1000 .

\subsection{Credit management cost}

With the rapid development of the Internet and mobile Internet, financial intelligence has become the main direction of the development of the financial sector. Due to the traditional credit reporting system using the "credit report and value-added services" model, which can not meet the needs of financial intelligence on the depth of data mining and rapid analysis of data. At this time along with 
the arrival of the era of big data, came into being the big data credit, thus meeting the needs of the financial intelligence of credit update.

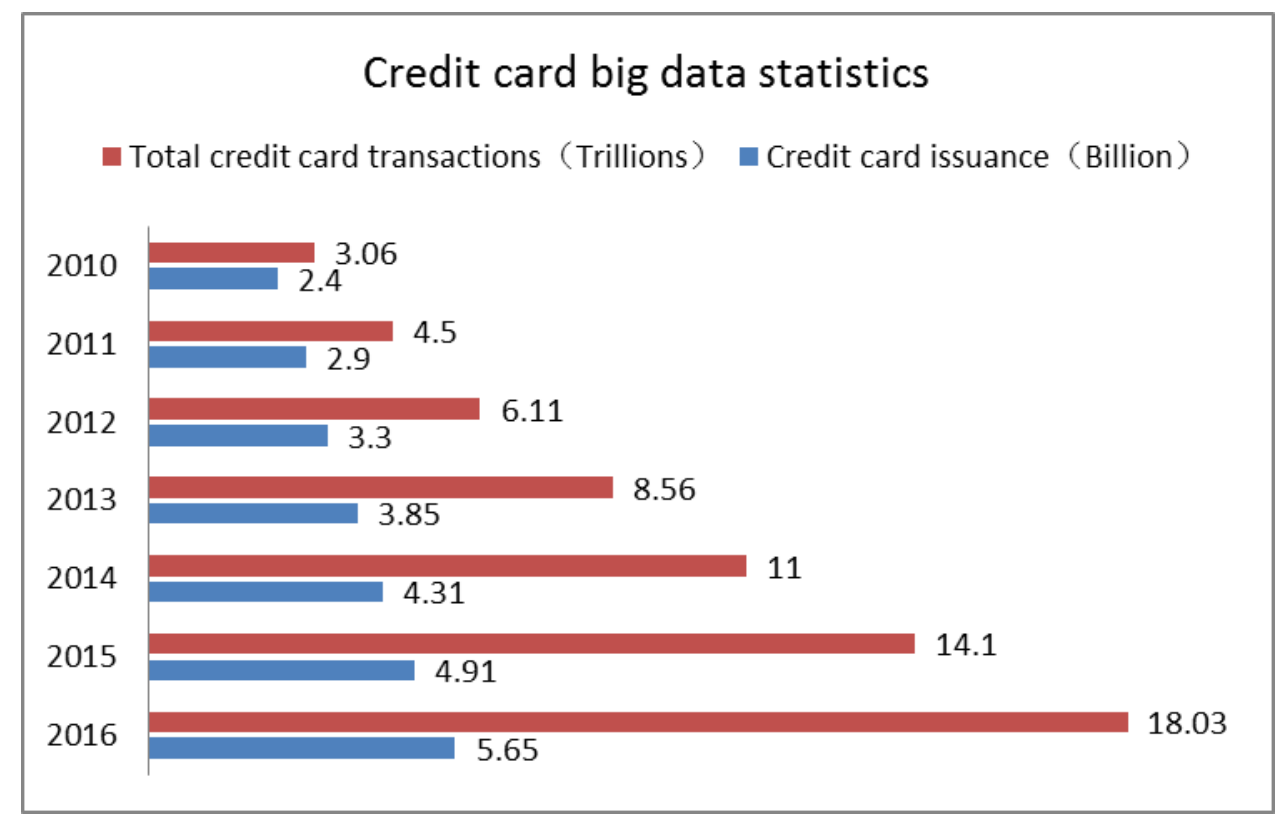

Fig.2 Credit card big data statistics

Large data collection and storage of large amounts of credit related data collection, and thus in-depth data mining and processing, which is a highly integrated information technology and financial products. Using search engines to crawl in the Internet business data, social network data, the third party payment data, credit card data as shown in figure 2 at the same time provide a combination of partners, with huge amounts of data, analysis the results of data analysis by using the cloud platform, guide the system to make judgments and decisions, credit evaluation results output per person. The multi-dimensional data has also increased exponentially, data storage is also facing great pressure, in the cost of credit management, with the arrival of the era of big data, Internet financial security and privacy issues in the big data to promote the credit situation becomes severe, the need to optimize the pattern of credit market, promote the transformation and upgrading of the credit industry and expand credit data sources.

\section{The impact of financial intelligence on the transaction cost of commercial banks \\ 3.1 Asset management field}

A large number of Internet transaction data provides support for the rapid development of Internet banking. Through the Internet platform, the Internet financial enterprises can be low-cost, efficient mining of large amounts of data, the accumulation of customer transaction information, in order to carry out customer financial needs analysis and risk assessment. For Internet companies to obtain information superiority, commercial banks should vigorously develop new Internet business, in the field of asset management, the next line of business to online business, enhance existing business ability, improve the business structure, strengthen exchanges with customers directly, and thus the stability of existing customers. As a representative of emerging information technology, big data has been widespread concern, the development of Internet banking and other industries can not be separated from the support of big data. Internet companies use their platform to build up a large number of customer transactions and credit data, through large data analysis of customers and constantly tap their personalized requirements. In order to establish a scientific and quantitative liquidity assessment model, we can not only grasp the customer's financial needs, but also reduce the risk of the transaction. At the same time, commercial banks should attach importance to the needs of Internet talent and technology, increase the cost of investment in the field of asset management, training and absorption of both financial and Internet technology to understand the talent. Only 
through the analysis of relevant personnel and technology, to provide effective decision-making data for banks, in order to ensure that commercial banks in the era of big data to keep up with the pace of progress of the times.

\subsection{Payment and settlement}

Based on the mobile payment, the payment mode of financial intelligence is to transfer the value of money through the mobile communication equipment and the wireless communication technology. Under the mode of financial intelligence, the payment between merchants and customers will be completed by third parties, or weaken the position of commercial banks as the traditional payment platform.

With the rapid development of Internet banking, the third party payment platform as the representative, the momentum of development can not be overlooked. And the wide application of the third party payment platform has posed a threat to the bank's payment and settlement status. Third party payment is a financial business led by Internet companies, the platform plays a role of intermediary and temporary storage. Although the third party platform business threatens the bank's settlement payment business, but still can not completely replace the bank. Payment and settlement through the Internet is an extension and supplement to traditional financial services. In response to this, the bank should increase the cost of investment, extensive cooperation with Internet companies. Using the third party payment institutions to master a large number of customer information, the bank for customer data analysis. And through cooperation with banks, Internet banking companies can promote their services and improve the reliability of the customer's heart. Through this partnership, the two sides with each other's advantages can meet the changing customer consumption brought new demands, such a more extensive and stable third party payment platform to attract more customers, provide more quality services for the

\subsection{Information authentication field}

With the rapid development of economy, China's domestic banks have entered the stage of rapid development. The bank's telephone banking, online banking, mobile phone banking and other electronic channels increasingly expanded and improved; at the same time, the bank customer transaction security, authentication tools diversity and ease of use are also highly concerned and increasing demand. However, the current mainstream user name password based authentication is a kind of weak authentication methods, because of its easy to guess, illegal interception of weakness in the current bank application environment has been unable to meet the security needs of the bank information system. Under the above background, identity authentication security bank information system in the research and construction of information security has become a priority among priorities of the first safeguard, it is generally considered the first step in the construction of banking information security.

\section{Policy suggestion}

(1) Establish a multi-cooperative digital bill system, to promote the multi-center notes Trading Intelligent digital draft system is safe and convenient to operate, more innovative space. For the electronic paper bills and electronic bills to accelerate the development of the construction of electronic bills exchange provides a very broad space, greatly enhance the possibility of building electronic bills exchange. It does not need to exchange data with ECDS system, realizes to the center function, enterprises and banks are to simplify the work process cumbersome paper form. It guarantees the authenticity and validity of the acceptance, guarantee and pledge of negotiable instruments. Open continuous block recording, to achieve the point of transaction, to a certain extent to achieve the "safe mode and efficiency to intermediary".

(2) Based on the development of block chain credit from the financial platform to intermediary and instant payment 
Block chain technology in recent years by the Internet and other professionals in the field of the blitz, which was widely praised as one of the next generation of global credit certification and value of the Internet based protocols. Its emergence indicates that the use of the Internet may shift from traditional information transmission to value transfer, thus bringing unprecedented challenges and challenges to the traditional financial industry. Block chain technology can greatly improve the efficiency of capital markets and financial institutions, or may cause the function part of the market disintermediation. Trading settlement of stocks, foreign exchange and credit may be completely changed due to the introduction of block chain technology. To cross-border payments, for example, in the traditional mode of payment requires two to three days of processing time, and the chain of the chain using a point to point payment only a few seconds to a few hours to achieve immediate payment.

(3) Build a digital identity sharing platform between banks to understand customer needs and reduce financial risks

Building digital identity sharing platform is the means and tools to build the basic platform of information application. It is to set up a high-level application platform in the bank management level, to achieve interoperability and data sharing. Data sharing center is an application oriented, safe and reliable, easy to operate, advanced technology, standardized, flexible and scalable system. Financial institutions can share information through the block chain trading entities, which will reduce a large number of repetitive work, but also save a lot of compliance costs for each institution. At the same time, this will provide great help for financial institutions to tap potential business opportunities, identify risk exposure.

\section{References}

[1] Wang J. Analysis on the Form of Internet Finance and Its Impact on Commercial Banking from the Perspective of Financial Functions[J]. Finance \& Economics, 2015.

[2] Yang C. A Study on Meteorological Service Supply Mode from the Perspective of Transaction Cost[C]// International Joint Conference on Computational Sciences \& Optimization. IEEE Computer Society, 2011:908-912.

[3] Liang T. The Impact of Interest Rate Marketization Reform on Financial Constraints of China's Enterprises from the Perspective of Credit Management[J]. Journal of Shenzhen University, 2015.

[4] Yoon S H, You Y Y. A Study on the Effects of Small Enterprises' Motivations to Request Consulting from the Perspective of Transaction Cost Economics and Sociological Neoinstitutionalism[J]. Indian Journal of Science \& Technology, 2015, 8(S7):581.

[5] Wang Y, Qi H, Liu Z, et al. The Engineering Stakeholders' Contradiction Analysis of Multinational Oil and Gas Pipeline from the Perspective of Transaction Cost[M]// Proceedings of the Third International Forum on Decision Sciences. Springer Singapore, 2016:31-37.

[6] Li-Na L V. Discussion on Giant Department Reform from the Perspective of Transaction Cost Theory[J]. Journal of Hubei University of Economics, 2009.

[7] Bogt H J T. A Transaction Cost Approach to the Autonomization of Government Organizations: A Political Transaction Cost Framework Confronted with Six Cases of Autonomization in the Netherlands[J]. European Journal of Law and Economics, 2003, 16(2):149-186.

[8] Liu Y F, Zhu H, Zhai Y J. On University Teachers' Laziness from the Perspective of Transaction Cost[J]. Journal of Huaihai Institute of Technology, 2013. 